Boise State University

ScholarWorks

Communication Faculty Publications and

Presentations

Department of Communication

$7-1-2014$

Having the Last Word, but Losing the Culture Wars: Mainstream Press Coverage of a Canceled Evangelical Benediction.

Rick Clifton Moore

Boise State University 


\title{
Having the Last Word, but Losing the Culture Wars: Mainstream Press Coverage of a Canceled Evangelical Benediction
}

\author{
Rick Clifton Moore, Ph.D. \\ Associate Professor \\ Department of Communication \\ Boise State University \\ rmoore@boisestate.edu
}

\begin{abstract}
This study examines how mainstream news media reported the withdrawal of a popular pastor from the 2013 Obama inaugural ceremony. Louie Giglio was originally chosen for a role in the event, but relinquished his position when focus was placed on a sermon he once delivered about homosexuality. Analysis of framing and sourcing of the stories raises serious questions about the role media played in reporting about this skirmish, which is clearly part of the larger culture wars.
\end{abstract}

\section{Introduction}

At the end of Barrack Obama's second inauguration ceremony, the Reverend Luis Leon, rector of St. John's Church in Washington, D.C., offered the benediction. His words brought closure to a rather unusual turn of events amid all of the festivities. Originally, the president's inauguration committee had chosen another cleric to deliver the blessing. The initial selection was Reverend Louie Giglio, pastor of Passion City Church, in Atlanta, Georgia. Giglio was not nationally known, but was widely recognized in the evangelical Christian church. Less than two weeks before the scheduled event, however, he stepped away from the duty of leading the nation in prayer. When he made that move, he stated that he did not wish to become mired in a debate over homosexuality, an issue which his selection as a speaker appeared to draw to the forefront.

The study that follows examines how the most powerful news outlets in the country framed Reverend Giglio's withdrawal, and reactions to his decision. In examining this unusual case, I hope to build on earlier research which has investigated the framing of religion, especially as it plays a role in social or political debate. More specifically, though, I wish to examine the extent to which the Giglio case might manifest notable change in how the American media portray religion's role in cultural debates such as the acceptance of gays and lesbians in society.

\section{Symbolic Conflict over Homosexuality, Religion and Media}

This investigation is oriented toward a view presented by Gamson (1981), a perspective that suggests significant societal conflict is evident in how social controversies are portrayed in the media. As Gamson points out, a conflict "draws on a catalogue of available idea elements" (p. 79). And, much of the struggle relates to interpretation and understanding of those idea elements. Bakelaar (2002) nicely summarizes Gamson’s vision.

Central to Gamson's method is the idea of symbolic conflict. In each public controversy, Gamson sees advocates involved in a context to promote acceptance of various particular interpretations. By using specific metaphors, depictions, exemplars, catchphrases, and visual images, advocates seek to frame issues. (p. 174)

Bakelaar, in his use of "frame," is blending Gamson with Goffman and with Entman, who both provided insights into how "framing" plays a role in the type of symbolic conflict introduced here. Goffman (1974) saw frames as a means of developing a common understanding among a group of people. They do so by highlighting certain ideas and ignoring others. Entman (1993) elaborated on this, suggesting that frames "call attention to some aspects of reality while obscuring other elements” (p. 55). Symbolic conflict, then, occurs when groups with very different views of reality play a role in shaping communication. Whether they know it or not, these bodies of citizens create 
messages that have a role in determining what others think about reality. As one scholar described it in regard to newspaper coverage of a contemporary social debate, "defining the terms used to describe social life is an important form of power because it privileges some moral claims over others” (Shortell, 2011, p. 433).

In recent conflicts and controversies regarding human sexuality in American society, then, scholars should be examining how the media frame issues and how those frames might legitimize or call into question certain interpretations of concrete experience. More succinctly, as Bakelaar intimates, researchers should examine how advocates of particular issues are allowed to speak, and the weight given to their interpretations. Scholars have engaged in significant study in the area of how the media portray the attempts of gays and lesbians to develop societal acceptance, but have provided little insight into how the media depict religion when it is a part of that struggle.

\section{Media Portrayal of Homosexuality}

At one time, scholars aptly described the media as being oblivious to American debate about gay rights, and even blind to the presence of gays and lesbians within their culture. Authors of one recent study, for example, boldly stated that there was a time when lesbian characters were "non-existent in American television programs" (Lee and Meyer, 2010, p. 234). With increasing presence of gay and lesbian issues in the news and in entertainment media, however, scholars have begun to delve into this "understudied area” (Moscowitz, 2010, p. 25), providing initial opportunities to discern how media frame controversies about homosexuality.

Whether an increase in presence leads to an increase in acceptance is still open to question, however. About fifteen years ago, one long-term study by Bennett (1998) examined how Time and Newsweek covered gays and lesbians over a fifty year period. She found that though the campaign for equal rights increased visibility, it did not lessen certain negative images. In this context, Bennett noted gays and lesbians were still described as a "threat" (p. 10). One of the ongoing problems Bennett (1998) observe in the news coverage of issues related to homosexuality was the "quoting of contemptuous labels" (p. 1).

Even very recent scholarship on very recent media imagery reveals media coverage that is not satisfactory to those who wish to see social change in this area. Pan, Meng and Zhou (2010) found that some media organizations have become very supportive of some gay and lesbian issues, such as same sex marriage, but others have not. They studied two major newspapers and found that the ideological orientation of the publications was a significant factor in predicting change. With similar mixed results, a recent examination by Schwartz (2011) of how four major newspapers reported about same-sex marriage determined that men were used as sources three times more often than women and that a higher number of negative statements were made about the issue than were positive statements.

These studies that show both positive and negative trends (from the perspective of a gay rights advocate) evince the uncertainty some scholars feel toward the overall media tendency to - in Gamson's words - "promote acceptance of various particular interpretations." Whether a particular interpretation of homosexuality currently reigns in the press is open to debate. One group of scholars, for example, though finding that gay rights supporters appear to have managed to get their frames to be used by media more than gay rights opponents, said the accepted frames "only minimally challenged normative conceptualizations of gender or the family.” (Liebler, Schwartz \& Harper, 2009, p. 670). Similarly, Moscowitz (2010) summed up the overall tone of much of this research.

Critical-cultural scholars argue that the rise in entertainment appeal and the recognition of gays and lesbians as a budding consumer market has not necessarily challenged homophobia or called into question heterosexual privilege. (p. 26)

She claimed that greater coverage is evident, but it contributes to a "feel-good veneer" that does little to reduce discrimination experienced by gays and lesbians (p. 24). The researcher further explained that in television news coverage of the same-sex marriage debate, gays and lesbians are "largely seen but not heard" (p. 36) 


\section{Media Portrayal of Evangelical Christians}

Interestingly, as Hicks and Lee (2006) have demonstrated, religiosity is one of the most powerful predictors of attitudes toward same sex marriage, second only to self-identification with liberal ideology. In general, "affect toward the traditional Judeo-Christian religious denominations" is strongly and negatively related to support for same-sex marriage (Gaines and Garand, 2010, p. 559). The authors of the aforementioned study also share that evangelical Protestants, specifically, are less supportive of same-sex marriage than other religious groups (p. 560). Religious predispositions are a strong enough factor in attitudes toward issues like same-sex marriage that they attenuate the influence of other variables such as media consumption (Becker and Scheufele, 2009).

Given those findings, one might be inclined to desire more knowledge of the mass media's dealings with the overtly religious, as much as with those who champion greater acceptance of, and rights for, gays and lesbians. More narrowly, having information about how media interact with Christians could be beneficial. And, finally, understanding of media interaction with evangelical Christians, such as Reverend Giglio, could be very useful to the present discussion.

This transition from more abstract "religion" to less abstract "evangelicals" can be seen in the research literature. Though Hoover and Venturelli (1996) once referred to religion as the "blindspot" of media theory, and only a small amount of scholarship was available in that amazingly broad area, numerous academics have begun stepping into the void. Some have examined religion broadly, with scholars such as Silk (1995) and Underwoood (2002) examining the historical American landscape to make the argument that media treat religion fairly. Initiation of the Journal of Media and Religion has allowed for ample study at a more concrete level, providing scholars with an outlet for research into media treatment of a wide variety of religious groups. Within $J M R$, for example, academics have examined media content related to how the press portrayed Mitt Romney's Mormon faith (Baker \& Campbell, 2010), to portrayal of Islam in relation to terrorism (Ewart, 2012) and even Taoism in popular music (Lee, 2012). Continued work needs to be done in all areas, and especially in relation to evangelical Christianity, an extremely important dimension of American culture, with about twenty percent of the population declaring themselves to be in that category (Pew, 2012). Little has been done, for example, to specifically study how evangelicals have been portrayed in news media. Kerr and Moy (2002), and Kerr (2003) engaged in groundbreaking work about how media treat "fundamentalists," a group that has some overlap with evangelicals in the contemporary religious landscape. Their findings indicate that news coverage generally tends to be somewhat cool, or negative. More recently, Haskell (2011) had studied evangelicals specifically, but has done so in the context of Canadian politics and media. Quite apropos, however, Haskell's analysis veered specifically into some of the issues at hand. He investigated how media covered evangelicals' messages in opposition to same-sex marriage legislation, and in doing so, found that many of the arguments the religious body expressed were either omitted or ignored.

Work gathered in one volume by Claussen (2002) examined some of the issues of interest to Haskell (2011), with a greater focus on the United States experience. In that volume there is a closer linkage with some of the issues to be analyzed in this paper. For example, Brackett-Vinyard (2002) studied a variety of popular magazines and demonstrated they tended to use fallacious arguments when writing about Donald Wildmon, a frequent critic of America's changing views on sexuality (including increased acceptance of homosexuality). Vela McConnell and Stratton (2002), questioned how religious viewpoints on homosexuality are expressed, but specifically within ideologically aligned websites, not mainstream news media. Earnest (2002) examined the specific nexus of media, religion and gay/lesbian rights, but in an essay that argued for particular rhetorical strategies for ascertaining those rights. Finally, demonstrating that these various studies leave much to be uncovered, Bakelaar (2002), alluded to the importance of continuing to analyze how the media operate as symbolic channels. He suggested that arguments over issues such as same-sex marriage are at a "stalemate." But, he shared that perception over ten years ago. The case of Louie Giglio’s abdication of the inaugural podium allows for renewed examination of those issues.

\section{Method}

The goals of this analysis were to examine how Reverend Louie Giglio's selection to and withdrawal from a role in the Obama inaugural event was portrayed, especially in light of his earlier preaching on the topic of homosexuality. In deference to terminology from Bakelaar, presented above, the assumption was that news is an area of symbolic conflict where advocates of particular ideas attempt to have those ideas validated in the media. The investigation thus called for two areas of inquiry: how the story was framed; and whose views the media shared and validated. 
Frame analysis, an approach originally generated from Goffman's (1974) theoretical perspective, has grown in importance in the study of media and religion (Stout \& Buddenbaum, 2003). Scholars have consistently pointed out that media create frames which Stout and Buddenbaum (2003, p. 1) see as "the products of a journalists' perceptions and a business organization's effort to attract audiences.” Source analysis is another way of investigating the key issues discussed here. Who is allowed to speak, and what is done with their words is a significant factor in the overall power of the various parties within the media interpretation (Fico and Soffin, 1995).

To analyze frames and sources requires that a set of media artifacts be examined. In this case, I performed a LexisNexis search for all stories in the month of January 2013 that included "Louie Giglio." The search included U.S. newspapers, magazines, and mainstream web sites such as cnn.com. I only considered text-based stories, so reports that were broadcast on radio or television with no transcription to a web page were left out for the immediate purposes of this study.

There are, of course, drawbacks to using a specific database and limiting the analysis to text, but there are advantages also. Using LexisNexis exclusively may have prevented analysis of some stories which occurred in mainstream media not included in the database. At the same time, it prevented any selection-bias on the part of the researcher. Focusing on text alone, rather than photos or video, does ignore very powerful means by which many audience members gain cues on social conflict, but also allows for increased clarity for this first attempt at analyzing the situation.

Following the example of Moscowitz (2010, p. 30), I eliminated stories that were only marginally connected to the inauguration controversy. And, as the current investigation relates to news media processes and values, only news reports of the event were used, not editorials and/or letters to the editor. The pastor's selection and withdrawal from the event needed to be the focus of the stories. A student assistant determined which stories were originals, published in prominent national media, and which were copies obtained by smaller media outlets through wire services such as the Associated Press. Only original stories, not duplicate publications in smaller outlets, were studied. A total of twenty-one stories from major news organizations were found. ${ }^{1}$ For the analysis, I worked inductively, reading and re-reading all stories in attempt to best understand the main frames that appear to have been imposed on the story. Initial reading required the extraction of all quotations for analysis of source trends. As the analysis was text-based, particular words rose to prominence. As I will explain later, I feel the words adequately represented particular themes from stories, and many stories shared particular themes. I also found that who was invited to speak, and what was shared from those individuals was reflective of key themes. And, in addition, how words were grouped, and placed in quotations was very important. What follows, then, is a discussion of how the story was framed, who was invited to speak, and the approach the reporters took to the voices of various parties in, and related to, the event.

\section{Analysis}

Though some aspects of this news story are rather unclear, the initial elements of it are evident. On the $8^{\text {th }}$ of January, 2013, the Presidential Inauguration Committee announced that Barrack Obama had selected Pastor Louie Giglio as one of two people who would "offer prayers at his ceremonial swearing-in" (Obama Inauguration, 2013). Shortly after the announcement, some began to question the selection. For example, a web site called ThinkProgress posted a story noting that Giglio was to deliver the inaugural benediction and that he had once preached a "vehemently anti-gay sermon" (Israel, 2013). As these expressions of discontent rose, one of two events occurred. Either the Presidential Inauguration Committee asked Reverend Giglio to step down, or he volunteered to do so. Whichever was the case, on Thursday, two days after the initial announcement of selection, Giglio shared a statement on his church website wherein he declared his withdrawal (Giglio, 2013). The Presidential Inaugural Committee also released a statement, one in which they claimed they were unaware of the sermon and would be seeking a new speaker. ${ }^{2}$

\section{Framing the Story}

Tankard (2001) has suggested that much of the process of framing a story can occur in the lead, wherein an overview of the narrative is revealed by the reporter. The word choice for these opening lines has significant bearing on how the news consumer perceives the whole. As will be discussed later, the frame developed early in the story was often maintained throughout. For the event in question, the key themes of reports provided several avenues for 
understanding the events. Those were "criticism," "controversy" and "evidence.” Differences between the most common themes were subtle. And, a very small number of stories did not seem to fit into any of these categories, with a few crossing boundaries between frames. Even so, I will argue below that their differences might matter in a symbolic conflict about a debated cultural topic. And, I will argue that the varying amounts of their usage favored one side of the struggle more than another.

Focusing on "criticism" follows an established journalistic norm, as it seems to fit the conflict frame that is commonly used in American journalism (Neuman, Just, \& Crigler, 1992). In addition, of course, the conflict frame is well established in the broader culture war. Liberal proponents of gay rights are presumed to be at war with conservative evangelical defenders of traditional marriage. In the Giglio story, criticism came from the first group aimed at the second. Three reporters (2013; Karl, 2013; Marrapodi, 2013; USA Today, 2013) actually used the word "criticism" in the lead. One used a similar concept in "complaints" (Boyer \& Wetzstein, 2013). Another described Giglio as "coming under fire" (Frumin, 2013). The USA Today story gives a good vision of the overall frame. It said:

The minister selected by President Obama to deliver the benediction at his inauguration later this month has withdrawn himself from the celebration after facing criticism for remarks he made about homosexuality in a sermon in the mid-1990s.

Culturally speaking, one might argue that the criticism frame reflects a reasonably neutral journalistic posture, given that an initial questions one rises upon seeing it in the news is whether the criticism is justified. Many people and groups who appear in the newspaper each day are objects of criticism. The job of the media is to present the criticism and then allow the target of the criticism to address it and help the public determine its validity. The leads of these stories, thus, seemed to be following a reasonable cultural norm.

Similar to "criticism," many reporters used the "controversy" frame. And, in this instance, four news reports used the precise word "controversy.” For example, Neela Banerjee (2013), of The Los Angeles Times, wrote:

An evangelical minister who was asked to give the benediction at President Obama's inauguration ceremony pulled out of the event Thursday after a controversy about comments he made against homosexuality in the 1990s.

The key contrast between the earlier frame of "criticism" and this one ("controversy") is important. Criticism needs a source, even if a reporter avoids divulging the source through the use of passive voice. Controversy can be seen as simply erupting spontaneously. We can note, for example, the spontaneity painted in the report of The New York Times, when it revealed that Giglio's withdrawal put "an end to a developing controversy.” The word "developing” does not imply a proponent of the controversy. It was simply happening. And, for the one report that suggested controversy has sources, the source was not the other side of the culture war (for example, the group ThinkProgress, which questioned Giglio's selection), but the selection of the speaker per se. Specifically, The Atlanta Journal reported the controversy as follows:

The Rev. Louie Giglio, whose selection to deliver the inaugural benediction sparked nationwide controversy because of his conservative views on homosexuality, dropped out of the coveted spot on Thursday.

Here, if there was a source of controversy, it was the pastor, not his opponents. Unlike the "criticism" frame, then, the "controversy" frame blurs the vision of the culture war by ignoring the key role contesting parties play in the debate.

The third common frame was perhaps more strongly predisposed against the evangelical pastor. That one, which will be labeled the "evidence" frame, was clearly used by eight different news sources (Boorstein \& Nakamura; Condon, 2013; Fox News, 2013; Jennings, 2013; Seitz-Wald, 2013; Straw, 2013; Williamson, 2013; Zoll, 2013) in the portion of the story that laid out the key issues. For example, Natalie Jennings, of The Washington Post wrote: 
This is an author-produced, peer-reviewed version of this article. The final, definitive version of this document can be found online at the Journal of Media and Religion, published by Taylor \& Francis. Copyright restrictions may apply. doi: 10.1080/15348423.2014.938978

An evangelical pastor from Atlanta announced Thursday that he would not give the benediction at President Obama's swearing-in ceremony after a sermon he gave on homosexuality in the mid1990s resurfaced earlier this week.

In this view, the "resurfacing" of the sermon was the key factor. Other reporters used a similar term ("surfaced"3), or spoke of the "revelation" of the sermon, or that it "came to light." Midway through her story in which she led with the concept of "surfacing," Stephanie Condon of CBS News elaborated that the sermon was "uncovered." Similarly, Zoll said the sermon "surfaced" and in a later paragraph matter-of-factly stated that ThinkProgress (not listed as "critics") merely "posted audio of the sermon." In all cases, the focus was not on criticism, nor on controversy. The selected words indicated that the mere fact that the sermon came before the public would be enough to cause great problems for the speaker.

Regarding the totality of the three frames, I should point out that they sometimes overlap. In Condon's story, for example, the dominant frame was the evidence that arose against Giglio. (It "surfaced," or was "uncovered.") At the end of the story, the journalist compared this "controversy" with the 2009 inauguration, when Rick Warren was accused of being insensitive to gays and lesbians.

In other cases, however, reporters clearly revealed a frame at the beginning and the end of a story. Aliyah Frumin of MSNBC began her story with the "criticism" frame, noting how Giglio had come under fire, then ended by reminding readers of the Warren imbroglio, using nearly identical words, "under fire," there. CNN had one of the most lengthy stories studied here, and maintained a "criticism" frame throughout, using that word in the lead, reemphasizing it in the middle, and ending with a quote in which a supporter of the pastor responded to his "critics." Sheryl Stolberg of the New York Times showed a persistent attachment to the "controversy" frame, using that in the lead (as noted earlier), and then returning to the theme near the end of the report, where she referred to the Warren event four years earlier with an identical term. Another controversy-frame story (Tenety, 2013) lead with the word "uproar," and soon reinforced that with a cute Biblical allusion, "And then God said, 'Let there be controversy.," She ended the article by noting similarities between this story and coverage in 2008 of the "controversial remarks" by Obama's pastor, Jeremiah Wright. Salon.com relied heavily on the "evidence" frame and reinforced it in the body of their story. At the end of the article they claimed that the selection of Giglio was "offensive" and raised the question of whether the inaugural committee really was "unaware of his anti-gay past."

\section{Sourcing the Subject}

I have suggested that beyond the notion of how a story is framed, another key factor in how symbolic conflict is manifest is the selection of sources. Once the story is presented in simple form through the lead, people are called upon to address it. Whom reporters select as sources plays an important role in what Bakelaar describes as symbolic conflict.

One factor researchers-and critics as well—often focus on is whether sources with differing opinions on the topic are given roughly equal treatment. Though no formal statistical analysis was done here, a simple quantification of sources in the stories revealed that reporters were generally fair to the various sides of the "controversy," as it was described above.

If stories would be described according to their balance toward greater reliance on pro or anti-Giglio sources, there was a larger number of stories in the latter category. That is, if reporters erred from equally using sources from both sides, they erred toward the side that favored more recognition of homosexual rights. Again, though, most reporters allowed one side of the controversy to speak, and then another. For example, some simply shared some words from the pastor, then words from the Presidential Inaugural Committee (after the P.I.C. had decided that Giglio was an unacceptable choice). ${ }^{4}$ Others relied upon third party experts, such as professors who do research in politics and religion. And, of course, some called upon traditional players in the culture wars to present the clearly-defined sides of those struggles. In use of these sources, some reporters failed to demonstrate an appearance of fairness. One news account (Boyer and Wetzstein, 2013), for example, showed a tilt toward the Giglio side, using quotations from Tony Perkins of the Family Research Council, Bryan Fischer of the American Family Association, and Samuel Rodriguez, who expressed disappointment in Giglio's withdrawal. One other story relied more heavily on pro-Giglio sources than anti. A total of five stories (Boorstein and Nakamura, 2013; Stolberg, 2013a; Stolberg, 2013b; Weinberg and March, 2013; Straw, 2013) relied more heavily on anti-Giglio sources than pro. To provide one example, Sheryl Gay 
This is an author-produced, peer-reviewed version of this article. The final, definitive version of this document can be found online at the Journal of Media and Religion, published by Taylor \& Francis. Copyright restrictions may apply. doi: 10.1080/15348423.2014.938978

Stolberg (2013a) of the New York Times quoted Wayne Besen of the group "Truth Wins Out” and John Aravosis of AMERICAblog. Both sources suggested that Giglio was an unacceptable choice to give the benediction. Stolberg quoted no sources who supported the pastor and his views.

In regard to the collection of stories as a whole, then, one might deem coverage reasonably balanced, with a slight favoritism toward the ThinkProgress position. One additional issue deserves further consideration, however. The main parties in the story (Pastor Giglio, ThinkProgress, and the Presidential Inauguration Committee) were all quoted frequently here, but, one group exerted power in the situation that was only visible upon close investigation.

Almost every one of the stories examined here used quotations from Louie Giglio's sermon on homosexuality. For sixteen of those stories, though, the pastor's views were highly filtered. Specifically, for sixteen of the journalistic reports studied here, every quotation provided from Giglio was one that ThinkProgress deemed worthy of transcribing onto their web site. Most of the journalists who provided reports of the incident decided that the portions of the fifty-four minute sermon that were important must have been the portions that the pastor's opponents felt were worth sharing with their constituency. Only one reporter appears to have gone beyond the perfunctory task of repeating what ThinkProgress posted. Elizabeth Tenety of The Washington Post provided a number of statements not quoted by the political group. Others appear to have trusted that the transcriptions they read were accurate. Rather embarrassingly, one story (Weinberg and Mach, 2013) inaccurately listed a paraphrase from the web site as a quote from the sermon.

\section{Mincing his Words}

A matter that is related to questions of source material and dependence on ThinkProgress for much of the text reported, but subtly different, is the issue of how certain distinct words from Giglio's sermon were used in these stories. As described below, reporters who covered the inauguration benediction decision often used very brief quotations from the Giglio sermon in a way that they did not for other sources.

To provide some context for this part of the analysis, I should point out that short, one or two word quotations are sometimes referred to popularly as "scare quotes." Unlike a lengthy quotation, which readers assume should be taken at face value, these word usages call meaning into question. Jowett and Peel (2010), in an analysis of UK newspaper coverage of same-sex marriage debates, suggest that scare quotes can problematize the use of the words quoted. Such can be a "neutralising device, distancing a writer from a 'controversial' phrase” (p. 208).

In the case studied here, one might speculate that some brief quotations encountered in the reports could simply have resulted from reporters trying to efficiently get their stories submitted on a deadline. That is, similar to the matter of relying on ThinkProgress for audio excerpts in general, reporters relied on the group's web site for short, pithy statements extracted from it.

Though such might be the case, Jowett and Peel's (2010) concerns still apply. When four mainstream news organizations borrowed the ThinkProgress website's use of the abbreviated two-word quotation "homosexual lifestyle" (Condon, 2013; USA Today, 2013; Weinberg and Mach, 2013; Zoll, 2013) did it show that the writers were - in Jowett and Peel's view — problematizing the use of the phrase? When three reporters (Frumin, 2013; SeitzWald, 2013; Weinberg and Mach) copied the web site and left "ex-gay therapy" as exclusive words in quotation marks, might this decision have acted as a "neutralizing device"? When two newspapers (Karl, 2013; Suggs \& Malloy, 2013) did the same for "recovery" might the effect have been similar? To summarize, news organizations consistently borrowed ThinkProgress' use of scare quotes, reproducing them without any apparent concern for how such abbreviated expressions stand out in a story and might affect news consumers' perceptions of the original speaker's words.

As noted above, the justification here might be the increasing pressure on newsrooms to meet deadlines with everpressing news cycles and smaller budgets for staff. The reporters who borrowed so faithfully from a partisan group's web site might have felt they had no time to dig up the words that were outside the boundaries of the secondary source's quotation marks. Worth noting, however, is how rare the use of scare quotes from sources other than Giglio were. For example, only one reporter (Marrapodi, 2013) chose to condense to one or two words any direct quotation 
from ThinkProgress (that is, words that they wrote about Giglio). Neither did any reporter choose to trim down to one or two words any quotation from the Presidential Inaugural Committee. With these observations in mind, justifying the discrepancy on the basis of news structure pressures is difficult.

More than this, the most troubling short quotation issue found in the texts could not be thus justified at all. Five news organizations (Boyer and Wetzstein, 2013; Fox News, 2013; Frumin, 2013; Seitz-Wald, 2013; Straw, 2013) chose to put the singular word "sin" in quotation marks. Unlike other brief quotations presented above, "sin" does not appear by itself anywhere on the ThinkProgress website. Yet, the word appeared in scare quotes in many mainstream news stories, as presented below.

...abruptly withdrew amid mounting complaints from gay-rights groups over his past comments condemning homosexuality and referring to it as a "sin." (Boyer and Wetzstein, 2013)

...has pulled out of the ceremony after comments surfaced in which he described homosexuality as a "sin." (Fox News, 2013)

....is also heard saying homosexuality is a "sin.” (Frumin, 2013)

... once denounced homosexuality as a "sin," warning that gay people will not go to heaven." (Seitz-Wald, 2013)

...he called homosexuality a "sin” curable by Christianity. (Straw, 2013)

On the ThinkProgress website, the group noted Giglio's selection and discussed 1990s sermon in general terms. They then offered transcriptions of excerpts. For each of those, there was a short paraphrase, presumably created by the author of the article. The wording of one paraphrase is, "Homosexuality is a sin." But, there are no quotation marks used anywhere within the paraphrase. That is, the word "sin" is not made to stand out from the rest of the statement. Moreover, in that section of the transcription of audio from the pastor's sermon, the word "sin" is used four times. For none of those four had the person who transcribed the audio chosen to put the single word "sin" in quotation marks. Why five reporters chose to do so cannot be determined from the text they created, but is worthy of consideration.

\section{Discussion}

Bakelaar (2002) suggested that there is a symbolic conflict in the media related to homosexuality, and that a key factor in that conflict is the ability of various sides to frame issues. Other scholars, cited earlier, who have studied media portrayal of debates on that topic have suggested that those opposed to greater visibility and rights for gays/lesbians have traditionally had the upper hand in this conflict. But, the analysis above paints a different picture. Whether the contrast with earlier research is due to limitations in the study, or changes in American culture, can only be addressed through further investigation.

To begin, though, reiterating the key findings is in order. Though "frames" are not clearly delineated and cannot easily be quantified, the pattern of usage here ("criticism," "controversy," and "evidence") seemed to indicate news portrayal that gave cultural advantage to ThinkProgress over Louie Giglio. "Criticism," a neutral frame that would have presented these reports as sideline views of two sides engaged in a conflict (making no judgment between the two) was used least frequently. "Evidence," a frame that suggested Louie Giglio had transgressed American values (and a frame that would suggest the values of groups like ThinkProgress are the country's legitimate values) was used most often.

In the area of sourcing and quotations, ThinkProgress also gained an upper hand. Third parties to the conflict who agreed with them were allowed to speak more than were third parties who supported Giglio. Of greater importance, almost all news sources relied very heavily on ThinkProgress and its web site to interpret the meaning of the pastor's earlier sermon. 
This is an author-produced, peer-reviewed version of this article. The final, definitive version of this document can be found online at the Journal of Media and Religion, published by Taylor \& Francis. Copyright restrictions may apply. doi: 10.1080/15348423.2014.938978

A final summary element from the analysis here provides further indication that Giglio's opponents fared very well in the symbolic conflict of the moment. Beyond depending on ThinkProgress for the quotes they used in their stories, news organizations also relied on the organization for their editing of those quotes. Specifically, they borrowed terse statements from the sermon to be presented in such a way that their meaning was called into question. As will be discussed later, some reporters even seemed to doubt the epistemological value of a fundamental element in Giglio’s world view.

Admittedly, all of the above findings need to be kept in the context of the current study, with all of its limitations. To note one potential deficiency, this was a single event, with a small number of stories covering the event. Examining future conflicts with similar cultural parameters would be beneficial. In addition, trying to better understand why media outlets choose to cover stories such as this, or not do so, would be valuable.

Here, I have chosen to study only mainstream news coverage as could be found within a single, well-respected, database. Given the popularity, and presumed power, of alternative news sources such as The Huffington Post, future research of similar events might also choose to examine alternative media, especially web-based channels. Moreover, the analysis here was limited to text. Devoting attention to photos and video in cases such as this is certainly warranted.

The limitations here, then, suggest numerous paths for future study in media, religion, and social conflict. And, even with those limitations, the findings of this study, in themselves raise intriguing questions for future scholarship. This is especially case in regard to the tendency of the media to use quotations, as they did in the context of this historical event.

For one, the clearly evident tendency of the press to rely so heavily on the ThinkProgress web site for framing the story raises numerous ethical questions. Is it appropriate to trust one partisan group for quotations of another partisan group's material? Did the accusing group accurately quote the work of the accused? Did the reporters consider the possibility that allowing one partisan group to condense another partisan group's material cedes power to the former? If Reverend Giglio spoke for over fifty minutes, and ThinkProgress presented approximately eight hundred words in quotations, why would reporters assume that the words from the web site are those most worthy of our attention and not delve into the full, original communication?

This aspect of the findings also raises suggestions for future research in a world where traditional news media are increasingly dependent on material from the web. How common is it for reporters to trust the websites of various groups involved in religious and social controversy? Do they tend to trust some groups more than others? In the Giglio case, it was a secular web site that introduced the story. When traditional news media organizations view web sites of religious bodies and find quotes from third party sources therein, do they tend to rely heavily on those quotes, or look at them with suspicion? Do they typically make the effort to go to the original source for verification?

Other questions arise over the use of very short, one and two word quotations from the ThinkProgress website. Are reporters conscious of the fact that they used the political group's editing to the extent they did? Why did so many of them decide to borrow abbreviated quotations for Pastor Giglio, while almost never doing so for ThinkProgress, and not doing so at all for the Presidential Inaugural Committee? And, why would professional reporters put quotation marks around a single word, which requires no quotation marks at all? ${ }^{5}$

In that vein, the decision by a sizable number of reporters to place the term "sin" in quotation marks is one of the most intriguing findings herein. As noted above, ThinkProgress provided no such usage on its web site. Reporters, then, made a decision on their own that this word was worthy of special consideration.

Earlier, the question was raised as to how this writing decision might relate to the widely recognized but little studied area of scare quotes. Two scholars who have given some thought to the subject suggest the following:

Scare quotes are a central and pervasive device for effecting distance. It enables speakers to indicate that they distance themselves, for whatever reason or in whatever way, from certain aspects of certain linguistic practices. (Cappelen \& Lepore, 2003, p. 56). 
This is an author-produced, peer-reviewed version of this article. The final, definitive version of this document can be found online at the Journal of Media and Religion, published by Taylor \& Francis. Copyright restrictions may apply. doi: 10.1080/15348423.2014.938978

Worth noting is that the "linguistic practices" from which reporters seem to have been distancing themselves were once practices that were deeply embedded in our culture. In the introduction to this paper, I cited Mark Silk's Unsecular Media and Douglas Underwood's From Yahweh to Yahoo, two studies that suggest those practices are still clearly evident in American media. For the "distancing” that seems implied by Cappelen \& Lepore's work on quotations, though, a better source of scholarship might be Quentin Schultze’s Christianity and the Mass Media in America. In that opus, he clearly describes a media system that has moved away from certain key theological dimensions of western religion, especially the concept of "sin." Indeed, he says that, "The concept of sin, as a distinctly religious contextualization of evil, has virtually disappeared from the mainstream media" (Schultze, 2003, p. 228). Going further, he claims:

As a biblical-theological construct, sin makes sense only in the context of a religious metanarrative that is too controversial for the news reports, sitcoms, and teen flicks of the day. (p. 231)

Here, Schultze's view offers a potential explanation why some reporters chose to set the word off from the rest of their story. Do some reporters assume the concept of sin, in and of itself, is no longer a mainstay of the broader culture?

Of course, these are important questions in a world that is rife with symbolic conflict, especially a world inhabited by many religious folk. If a sizeable group of citizens has, as part of its worldview, a vital term that some in the media have come to see as suspect, how are those citizens to take part in the debate? This question becomes more intriguing in light of recent scholarship by Haskell (2011) presented in the intro. In his work, he has found that when Canadian evangelicals attempted to use non-religious arguments to make their case against same-sex marriage, their message failed. Specifically, the press did not accurately represent their key arguments. Perhaps, if this is the often the case, evangelicals are damned if they use theological language, and damned if they do not.

If nothing else, then, the above study falls in line with Haskell's work from north of the U.S. boarder. It invites scholars to continue to investigate the part Christians such as Giglio are playing in contemporary social debates, and the extent to which the media are facilitating their role in the democratic process, or not. And, in that context, the present study stands in stark contrast to much of the research introduced in the opening pages. Many of the scholars cited above indicated that the religious right was faring very well in their culture wars. The key question thus becomes how to configure the above findings (and those of Haskell) with the earlier research which they appear to contradict. As an example, how do the findings of Haskell, and the material from the news stories above fit with the thorough work of Winston (2007), who in summarizing the role of religion in press coverage of sexuality has suggested, "it's not the mainstream media but rather the religious conservatives who have established the terms of the debate" (p. 979)?

The facts of this study suggested Giglio had little power in the current debate, in spite of sharing certain words with the public. Many broad questions ensue. Theoretically speaking, might Entman's (1993) description of how the media obscure some elements of reality fit very well with the way Giglio's weltanschauung was called into question? And, does Shortell's (2011) claim that the press "privileges some moral claims over others" (p. 433), make sense of the way the pastor's claims appear to have been placed very low on the axiological ladder? Scholars should continue to address questions such as these. And, they should look for opportunities to study events such as Louie Giglio experienced, scenarios in which key characters in a symbolic conflict appear to be allowed to speak, but might have little real power in the cultural battle raging around them. 


\section{REFERENCES}

Bakelaar, P. J. (2002). Issue culture analysis and the gay/lesbian religious controversy. In D. S. Claussen (Ed.), Sex, Religion, Media (pp. 171-182). New York, NY: Rowman \& Littlefield Publishers, Inc.

Baker, S., \& Campbell, J. (2010). Mitt Romney's religion: A five factor model for analysis of media representation of Mormon identity. Journal of Media \& Religion, 9(2), 99-121.

Banerjee, N. (2013, January 10). Pastor pulls out of Obama inauguration benediction. The Los Angeles Times. Retrieved from http://www.latimes.com/news/nationworld/nation/la-na-inaugural-pastor20130111,0,1750081.story

Barnhurst, K.G. (2003). Queer political news: Election-year coverage of the lesbian and gay communities on National Public Radio, 1992-2000. Journalism, 4(5), 5-28.

Becker, A.B., \& Scheufele, D.A. (2009). Moral politicking: Public attitudes toward gay marriage in an election context. International Journal of Press/Politics, 14(2), 186-211.

Bennett, L. (1998). The perpetuation of prejudice in reporting on gays and lesbians: Time and Newsweek: the first fifty years. Cambridge, MA: President and Fellows of Harvard College.

Boorstein, M., \& Nakamura, D. (2013, January 10). Conservative pastor drops out of Obama's inauguration because of 1990s anti-gay sermon. The Washington Post. Retrieved from http://www.washingtonpost.com/local/2013/01/10/25fb83bc-5b6e-11e2-88d0c4cf65c3ad15_story.html

Boyer, D. \& Wetzstein, C. (2013, January 11). Pressure from gays pushes pastor off inaugural agenda. The Washington Times. Retrieved from http://www.lexisnexis.com/hottopics/lnacademic/

Brackett-Vinyard, N. J. (2002). Magazine coverage of the man the networks love to hate. In D. S. Claussen (Ed.), Sex, religion, media (pp. 115-135). Lanham, MD: Rowman \& Littlefield Publishers, Inc.

Cappelen, H. \& Lepore, E. (2003). Varieties of quotation revisited. Belgian Journal of Linguistics, 17, 51-75.

Claussen, D. S. (Ed.). (2002). Sex, religion, media. Lanham, MD: Rowman \& Littlefield Publishers, Inc.

Condon, Stephanie. (2013, January 10). Pastor drops out of inauguration over anti-gay sermon. CBS News. Retrieved Form http://www.cbsnews.com/8301-34222_162-57563291-10391739/pastor-drops-out-ofinauguration-over-anti-gay-sermon/

Earnest, W. J. (2002). Between law and love: Christianity, politics, and sexual citizenship. In D. S. Claussen (Ed.), Sex, religion, media (pp. 197-213). Lanham, MD: Rowman \& Littlefield Publishers, Inc.

Entman, R. M. (1993). Framing: Toward clarification of a fractured paradigm. Journal of Communication, 43(4), 51-58.

Ewart, J. (2012). Framing an alleged terrorist: How four Australian news media organizations framed the Dr. Mohamed Haneef case. Journal of Media \& Religion, 11(2), 91-106.

Fico, F. and Soffin, S. (1995). Fairness and balance of selected newspaper coverage of controversial national, state, and local issues. Journalism and Mass Communication Quarterly, 72, 621.

Fox News. (2013, January 10). Pastor withdraws from Obama inauguration after sermon on homosexuality surfaces. Fox News. Retrieved from http://www.foxnews.com/politics/2013/01/10/pastor-withdraws-from-obamainauguration-after-sermon-on homosexuality-surfaces/

Frumin, A. (2013). Pastor bows out of Obama's inauguration over anti-gay sermons. Msnbc.com. Retrieved from http://tv.msnbc.com/2013/01/10/pastor-bows-out-of-obamas-inauguration-over-anti-gay-sermons/

Gaines, N. S., \& Garand, J. C. (2010). Morality, equality, or locality: Analyzing the determinants of support for same-sex marriage. Political Research Quarterly, 63(3), 553-567.

Gamson, W. A. (1981). The political culture of the Arab-Israeli conflict. Conflict Management and Peace Science, 5:79-94.

Giglio, L. (2013). Change of plans. [Web log comment.] Retrieved from http://www.passioncitychurch.com/blog/?p=1436.

Goffman, E. (1974). Frame analysis: An essay on the organization of experience. New York: Harper and Row.

Haskell, D.M. (2009). Through a lens darkly: How the news media perceive and portray evangelicals. Toronto: Clements Academic.

Haskell, D.M. (2011). "What we have here is a failure to communicate”: Same-sex marriage, evangelicals, and the Canadian news media. Journal of Religion and Popular Culture, 23(3), 311-329.

Hicks, G.R., \& Lee, T. (2006). Public attitude toward gays and lesbians: Trends and predictors. Journal of Homosexuality, 51(2), 57-77.

Hoover, S.M., \& Venturelli, S.S. (1996). The category of the religious: The blindspot of contemporary media theory? Critical Studies in Mass Communication, 13, 251-265. 
This is an author-produced, peer-reviewed version of this article. The final, definitive version of this document can be found online at the Journal of Media and Religion, published by Taylor \& Francis. Copyright restrictions may apply. doi: 10.1080/15348423.2014.938978

Israel, J. (2013, January 9). Inaugural benediction to be delivered by pastor who gave vehemently anti-gay sermon. Think Progress. Retrieved from http://thinkprogress.org/lgbt/2013/01/09/1422021/inaugural-benedictionto-be-delivered-by-anti-gay-pastor/

Jennings, N. (2013, January 10). Louie Giglio pulls out of inauguration over anti-gay comments. The Washington Post. Retrieved from http://www.washingtonpost.com/blogs/post-politics/wp/2013/01/10/louie-gigliopulls-out-of-inaugural-over-anti-gay-comments/

Jowett, A. \& Peel, E. (2010). Seismic cultural change?: British media representations of same-sex 'marriage'. Women's Studies International Forum, 33, 206-214.

Karl, J. (2013, January 10). Pastor backs out of Obama inauguration over previous anti-gay comments. ABC News. Retrieved from http://abcnews.go.com/blogs/politics/2013/01/obama-inauguration-pastor-steps-down-overprevious-anti-gay-comments/

Kerr, P. A. (2003). The framing of fundamentalist Christians: Network television news, 1980-2000. Journal of Media \& Religion, 2(4), 203-235.

Kerr, P.A. \& Moy, P. (2002). Newspaper coverage of fundamentalist Christians. Journalism and Mass Communication Quarterly, 79, 54-72.

Lee, J. (2012). "Everybody, Let's Tighten the Anus": Exploring the Social and Cultural Meaning of a Korean Folksong. Journal of Media \& Religion, 11(4), 216-230.

Lee, P., \& Meyer, D. E. (2010). We all have feelings for our girlfriends: Progressive (?) representations of lesbian lives on The L Word. Sexuality \& Culture, 14, 234-250.

Liebler, C. M., Schwartz, J., \& Harper, T. (2009). Queer tales of morality: The press, same-sex marriage, and hegemonic framing. Journal of Communication, 59, 653-675.

Madhani, A. (2013, January 10). Minister withdraws from inauguration over remarks. USA Today. Retrieved from http://www.usatoday.com/story/news/politics/2013/01/10/minister-obama-inauguration-remarkshomosexuality/1823541/

Marrapodi, E. (2013, January 10). Giglio bows out of inauguration over sermon on gays. CNN. Retrieved from http://religion.blogs.cnn.com/2013/01/10/giglio-bows-out-of-inauguration-over-sermon-ongays/?iref=allsearch

Moscowitz, L. M. (2010). Gay marriage in television news: Voice and visual representation in the same-sex marriage debate. Journal of Broadcasting and Electronic Media, 54(1), 24-39.

Neuman, W.R., Just, M.R., \& Crigler, A.N. (1992). Common knowledge. Chicago, University of Chicago Press.

Obama Inauguration. (2013, January 8). @BarackObama has chosen Myrlie Evers-Williams and Pastor Louie Giglio to offer prayers at his ceremonial swearing-in: http://bit.ly/VCLwCh. Retrieved from https://twitter.com/obamainaugural/status/288723157504913408.

Pan, P., Meng, J., \& Zhou, S. (2010). Morality or equality? Ideological framing in news coverage of gay marriage legitimization. The Social Science Journal, 47, 630-645.

Pew Forum on Religion and Public Life (2012). "Nones” on the rise: One in five adults have no religious affiliation. Washington: Pew Research Center.

Schwartz, J. (2011). Whose voices are heard? Gender, sexual orientation, and newspaper sources. Sex Roles, 64, 265-275.

Schultze, Q. J. (2003). Christianity and the mass media in America: Toward a democratic accommodation. East Lansing, MI: Michigan State University Press.

Seitz-Wald, A. (2013, January 10). Anti-gay pastor withdraws. Salon. Retrieved from http://www.salon.com/2013/01/10/anti_gay_pastor_dropped_from_inauguration_ceremonies/

Shortell, T. (2011). The conflict over origins: A discourse analysis of the creationism controversy in American newspapers. Mass Communication and Society 14, 431-453.

Silk, M. (1995). Unsecular media: Making news of religion in America. Urbana: University of Illinois Press.

Stolberg, S.G. (2013 a, January 9). Pastor chosen for inaugural was criticized as antigay. The New York Times. Retrieved from http://www.nytimes.com/2013/01/10/us/politics/louie-giglio-inaugural-pastor-criticizedfor-antigay-sermon.html?_r=0

Stolberg, S. G. (2013 b, January 10). Minister backs out of speech at inaugural. The New York Times. Retrieved from http://www.nytimes.com/2013/01/11/us/politics/minister-withdraws-from-inaugural-program-aftercontroversy-over-comments-on-gay-rights.html

Stout, D.A. \& Buddenbaum, J.M. (2003). Media, religion, and 'framing.' Journal of Media \& Religion, 2, p. 1-3.

Straw, J. (2013, January 10).Prominent pastor out of Obama Inaugural after revelation he called homosexuality a ‘sin’ curable by Christianity. Daily News. Retrieved from 
http://www.nydailynews.com/news/politics/pastor-inaugural-revelation-called-homosexuality-sin-article1.1237500

Suggs, E., \& Malloy, D. (2013, January 10). Atlanta’s Rev. Giglio withdraws from Obama inauguration amid controversy. The Atlanta Journal. Retrieved from http://www.ajc.com/news/news/atlantas-rev-gigliowithdraws-from-obama-inaugurat/nTsR9/

Tankard, J.W. (2001). The empirical approach to the study of media framing. In S. Reese, O. Gandy, \& A. Grant (Eds.) Framing public life: Perspectives on media and our understanding of the social world (pp. 95-106). Mahwah, NJ: Lawrence Erlbaum.

Tenety, E. (2013, January 10). Louie Giglio backs out of inaugural benediction over comments on homosexuality. The Washington Post. Retrieved from http://www.washingtonpost.com/blogs/under-god/post/louie-gigliobacks-out-of-inaugural-benediction-over-comments-on-homosexuality/2013/01/10/581a69de-5b29-11e29fa9-5fbdc9530eb9_blog.html

Underwood, D. (2002). From Yahweh to Yahoo!: The religious roots of the secular press. Urbana: University of Illinois Press.

USA Today (2013, January 10). Minister withdraws from inauguration over remarks. Retrieved from http://www.usatoday.com/story/news/politics/2013/01/10/minister-obama-inauguration-remarkshomosexuality/1823541/

Vela-McConnell, J. A. \& Stratton, B. J. (2002). The word on sex: Biblical interpretation on the web and constructed realities. In D. S. Claussen (Ed.), Sex, religion, media (pp. 183-196). Lanham, MD: Rowman \& Littlefield Publishers, Inc.

Weinberg, A. \& Mach, A. (2013, January 10). Pastor nixed from Obama inaugural over anti-gay remarks. MSNBC. Retrieved from http://usnews.nbcnews.com/_news/2013/01/10/16449097-pastor-nixed-from-obamainaugural-over-anti-gay-remarks?lite

Williamson, E. (2013, January 10). Pastor chosen for inauguration benediction bows out. The Washington Post. Retrieved from http://online.wsj.com/news/articles/SB10001424127887323442804578233821945528366

Winston, D.H. (2007). Back to the future: Religion, politics and the media. American Quarterly, 59, 969-989.

Zoll, R. (2013, January 10). Inaugural pastor withdraws over anti-gay remarks. The Denver Post. Retrieved from http://www.denverpost.com/ci_22347163/inaugural-pastor-withdraws-over-anti-gayremarks?IADID=Search-www.denverpost.com-www.denverpost.com

\footnotetext{
NOTES

${ }^{1}$ The number of stories found is interesting in itself. More attention is devoted to this in the discussion section.

${ }^{2}$ News stories speak of a statement from the P.I.C. Many cite it, and provide quotations from it. There does not appear to be a copy of the statement online at the time of the writing of this paper.

${ }^{3}$ Some of the basis for variants of the word "surfaced" was certainly that Giglio used the term in his explanation of the event (posted on the church's web site). As is discussed later, however, in many instances the theme was expounded much beyond use of the particular word. In addition, Giglio's blog entry had other colorful words that could have served as a frame for the news story. For example, the "criticism" frame could have been bolstered by Giglio’s claim that he was being dragged into "a fight on an issue not of our choosing” (Giglio, 2013).

${ }^{4}$ After Think Progress and others complained of their selection, a spokesperson for the committee said they were unaware of Giglio's sermon and that his words “don’t reflect our desire to celebrate the strength and diversity of our country."

${ }^{5}$ The Associate Press Stylebook suggests that reporters should avoid fragmentary quotes. It provides no definition of "fragmentary."
} 